IZA DP No. 10346

Wheeling into School and Out of Crime:

Evidence from Linking Driving Licenses to Minimum Academic Requirements

Rashmi Barua

Marian Vidal-Fernandez

November 2016 


\title{
Wheeling into School and Out of Crime: Evidence from Linking Driving Licenses to Minimum Academic Requirements
}

\author{
Rashmi Barua \\ Jawaharlal Nehru University \\ Marian Vidal-Fernandez \\ University of Sydney, \\ Life Course Centre and IZA
}

Discussion Paper No. 10346

November 2016

\author{
IZA \\ P.O. Box 7240 \\ 53072 Bonn \\ Germany \\ Phone: +49-228-3894-0 \\ Fax: +49-228-3894-180 \\ E-mail: iza@iza.org
}

Any opinions expressed here are those of the author(s) and not those of IZA. Research published in this series may include views on policy, but the institute itself takes no institutional policy positions. The IZA research network is committed to the IZA Guiding Principles of Research Integrity.

The Institute for the Study of Labor (IZA) in Bonn is a local and virtual international research center and a place of communication between science, politics and business. IZA is an independent nonprofit organization supported by Deutsche Post Foundation. The center is associated with the University of Bonn and offers a stimulating research environment through its international network, workshops and conferences, data service, project support, research visits and doctoral program. IZA engages in (i) original and internationally competitive research in all fields of labor economics, (ii) development of policy concepts, and (iii) dissemination of research results and concepts to the interested public.

IZA Discussion Papers often represent preliminary work and are circulated to encourage discussion. Citation of such a paper should account for its provisional character. A revised version may be available directly from the author. 
IZA Discussion Paper No. 10346

November 2016

\section{ABSTRACT}

\section{Wheeling into School and Out of Crime: Evidence from Linking Driving Licenses to Minimum Academic Requirements ${ }^{*}$}

Since the late 1980 s, several U.S. states have set minimum academic requirements for high school students to apply for and retain their driving licenses. These laws popularly known as "No Pass No Drive" (NPND), encourage teenagers with a preference for driving to stay in school beyond the minimum dropout age. Using Federal Bureau of Investigation (FBI) arrest data, we exploit state, time and cohort variation to show that having an NPND law in place is associated with a significant decrease in arrests due to violent, drug-related and property crime among males between 16 to 18 years of age. We argue that our findings are driven by an increase in education rather than incapacitation and that NPND laws are a relatively low cost policy that generates positive externalities beyond and in addition to the minimum dropout age.

JEL Classification: No Pass No Drive laws, juvenile crime, education

Keywords: $\quad \mathrm{K} 14, \mathrm{~J} 24, \mathrm{~J} 18$

Corresponding author:

Marian Vidal-Fernández

School of Economics

University of Sydney

NSW 2006, Sydney

Australia

E-mail: m.vidal-fdez@sydney.edu.au

\footnotetext{
* We thank Willian Evans and Fabian Waldinger for useful comments. Thanks to all participants at ISI Delhi growth and development conference, CWIP Workshop at Warwick University and the Spanish Economic Meetings in Santander for useful comments. Xuna Gao and Sughanda Huria provided excellent research assistance. The usual caveats apply.
} 


\section{Introduction}

Roughly 11.2 million offenders were arrested in the U.S. in 2014. Estimates of the monetary costs of crime range from around $\$ 9,000$ for vehicle assaults to up to $\$ 8.5$ million for murder. ${ }^{1}$ According to the Office of Juvenile Justice and Delinquency Prevention, nearly $20 \%$ of individuals arrested for violent crimes and more than $25 \%$ arrested for property crimes in 2006 were under the age of $18 .^{2}$ Boys represented $83 \%$ and $68 \%$ of juvenile violent and property arrests, respectively.

Most of the traditional labor economics literature focusing on crime analyzes how incapacitation, sanctions, prevention, and improved opportunities in the licit labor market reduce criminal behavior ${ }^{3}$. In recent years, there has been an increased interest in measuring the effects of policies not specifically targeted to reduce crime yet that have an indirect effect on criminal activities. Special attention has been paid to interventions that increase educational quality (Deming 2011; Levitt et al. 2006) or attainment (Lochner and Moretti 2004; Machin et. al. 2011). ${ }^{4}$

Reducing crime through education can yield significant welfare gains. For instance, Lochner and Moretti (2004) estimate that a one percentage point increase in male high school graduation rates in 1990 would have decreased crime by approximately 100,000 , saving $\$ 2$ billion to the public. In addition, higher levels of education are shown to generate further positive externalities through improved health outcomes and good citizenship (Lochner 2011b).

There are several theoretical channels through which education can lead to a decrease in crime. First and foremost, higher education increases expected wages and therefore the opportunity cost of working in licit activities. Second, human capital investments increase patience and the disutility of long-term punishments (Becker and Mulligan, 1997). Moreover, more patient individuals are less impulsive and therefore less prone to show an aggressive behavior that can foster crime. ${ }^{5}$

Third, education decreases other health risk-taking behaviors such as drinking (Cutler and Lleras-Muney 2012) that are associated with crime. Education may

\footnotetext{
${ }^{1}$ RAND Cost of Crime Calculator.

${ }^{2}$ Violent crime includes murder, rape, robbery, and aggravated assault. Property crime includes burglary, larceny, theft, and arson.

${ }^{3}$ For a review see Freeman 1999

${ }^{4}$ For a survey of both of these topics see Lochner (2011a).

${ }^{5}$ Psychological literature has also measured a positive correlation between aggressiveness and impulsiveness. An example of this research is Ramirez and Rodriguez (2006).
} 
also reduce accident rates or Driving Under the Influence (DUI) crimes if more educated individuals have higher discount rates and drive more safely (Barua and VidalFernandez 2014). Finally, highly educated individuals are more likely to interact with each other and therefore benefit from positive peer effects. This is key as peer effects have been found to be a very strong determinants of criminal behavior (Patacchini and Zenou 2009).

The aforementioned channels relate to the long-run impacts of education on crime. Nonetheless, the contemporaneous or short-run impact of schooling on crime is ambiguous. On the one hand, staying in school might have a deterrence or incapacitation effect if potential offenders do not have access to criminal activities or are being surveilled or screened. Jacob and Legfren (2003) and Luallen (2006) instrument missing school with teacher in-service and strike days, respectively. Both studies find important incapacitation effects of education on criminal participation because keeping juveniles in school limits their time to commit crime outside school. On the other hand, violent and non-reported crimes such as bullying or illegal drug use might increase directly if problematic teenagers are being forced to stay in school and indirectly if they generate a "rotten apple" peer effect (Anderson et. al. 2013).

This paper analyzes the effects of a law commonly known as No Pass, No Drive (NPND) that links access to driving licenses to school attendance and in some cases academic performance. Currently 26 states set minimum academic requirements for teenagers to obtain or retain driving licenses. Using data from the Federal Bureau of Investigation (FBI) and the Youth Risk Behavior Survey (YRBS), we exploit geographical, time and cohort variation in NPND laws to measure their effects on juvenile crime.

While NPND laws have been shown to increase high school graduation rates among males (Barua and Vidal-Fernandez 2014) and therefore could potentially decrease crime, the effects of NPND laws on crime are theoretically ambiguous and timedependent. NPND laws can have a deterrence effect by keeping potential juvenile criminals off the streets. However, these laws could also have a positive effect on crime if it encourages them to stay in school without changing their behavior.

Thus, the net effect of NPND laws will depend on whether the negative effect on crime through increased human capital and/or the incapacitation effect is greater than the potential increase in school crimes. Results from the preferred specification using FBI data confirm that NPND laws significantly reduce the incidence of all 
crimes, violent, drug and property crimes only among the affected cohorts of males (16 to 18 year olds). The largest effect is on drug-related crimes among both males and females.

Further, to explore crime-related behavior in schools, we analyze microdata from the Youth Risk Behavior Survey (YRBS). We find that NPND laws decrease the probability of missing school due to concerns of safety but have no effect on risky behavior among young adults of either gender.

We argue that the absence of the "rotten apple" effect can be attributed to the NPND law being non-binding. While NPND laws encourage students with a strong preference for driving to remain in school and increase their human capital, those with a strong preference for crime and who are also more likely to induce the "rotten apple" effect can drop out regardless.

Second, NPND laws have a strong impact on educational investments. In addition to enrollment, 19 of the 26 NPND states impose minimum attendance requirements, with some even imposing minimum academic ( 5 states) and good behavior (6 states) standards, in addition to school enrollment. Consistently, Barua and Vidal-Fernandez (2014) find that students who remained in school increased time allocated to schoolwork at the expense of leisure and work hours.

The contributions of this paper are threefold. First, this is the first paper analyzing the effect on crime of a policy that helps keeping 16 to 18 year olds with a preference for driving, to stay in school beyond the minimum dropout age. Given the evidence that the largest gains from crime reduction come from policies that encourage high school completion (Lochner 2011), NPND laws seem to be a relatively low-cost policy complementary to compulsory attendance laws. NPND Laws have been shown to increase male high school graduation by 2\% (Barua and Vidal-Fernandez 2014). Thus, following the estimates by Lochner and Moretti (2004), these laws could save the public up to 4 billion through social savings from crime reduction.

Second, we find NPND laws to be particularly effective for males, who are not only twice as likely to drop out from high school than females (Department of Education 2014) but also overrepresented in the inmate population.

Finally, this paper supports the recent evidence (Fryer 2016) that policies aimed at increasing human capital among disadvantaged teenagers might be as cost-effective as early childhood interventions. 


\section{No Pass No Drive Laws}

Table 1: Summary of CAL \& NPND Laws* (2010)

\begin{tabular}{|c|c|c|c|}
\hline State with NPND & $\begin{array}{l}\text { Min Age } \\
\text { NPND }\end{array}$ & $\begin{array}{l}\text { Max Age } \\
\text { NPND }\end{array}$ & $\begin{array}{c}\text { Dropout } \\
\text { Age }\end{array}$ \\
\hline Alabama & 13 & 19 & 16 \\
\hline Arkansas & 14 & 18 & 18 \\
\hline California & 13 & 18 & 16 \\
\hline Delaware & - & - & 18 \\
\hline Florida & 15 & 18 & \\
\hline Georgia & 15 & 18 & 16 \\
\hline Idaho & 15 & 18 & 16 \\
\hline Illinois & - & 18 & 16 \\
\hline Indiana & 15 & 18 & 18 \\
\hline lowa & - & 18 & 16 \\
\hline Kansas & 13 & - & 17 \\
\hline Kentucky & 16 & 18 & 17 \\
\hline Louisiana & 15 & 18 & 16 \\
\hline Mississippi & 15 & 18 & 16 \\
\hline Nevada & 14 & - & 16 \\
\hline New Mexico & - & - & 16 \\
\hline North Carolina & 15 & 18 & 18 \\
\hline Ohio & - & 18 & 18 \\
\hline Oklahoma & 14 & 18 & 17 \\
\hline Oregon & 15 & 21 & 16 \\
\hline South Carolina & 15 & 17 & 17 \\
\hline Tennessee & 15 & 18 & 18 \\
\hline Texas & 15 & 18 & 16 \\
\hline Virginia & 16 & 18 & 16 \\
\hline West Virginia & 15 & 18 & 16 \\
\hline Wisconsin & 16 & 18 & \\
\hline
\end{tabular}

${ }^{*}$ CAL refers to Compulsory Attendance Laws while NPND refers to No Pass No Drive laws

NPND laws deny or revoke drivers licenses to minors if they drop out of school, are frequent truants and/or have a low academic performance. West Virginia got considerable media attention after being the first state passing such as a law in 1988 because it experienced a significant decrease in dropout rates a year after of implementation (Ayres 1989). The media attention gave momentum to NPND in the early 90s when most of these laws were enacted. 
Table 1 gives the summary of states with NPND laws, the minimum age at which these law apply to students and the maximum age beyond which driving license is no longer conditional on school enrollment. Column 3 also shows the minimum drop out ages in the NPND states. As we can see, in the vast majority of states, NPND laws constrains students, who care for driving, to stay in school even beyond the minimum compulsory attendance age.

The State Department of Education, the Department of Public Safety and the Division of Driver's Licensing work together towards implementation of NPND. To apply for a driver license, a student is required to show a School Compliance Verification Form to prove that he is compliant with the NPND law. In some states, such as Kentucky and Florida, schools electronically report changes to their students' statuses to the licensing authorities. The online service is provided free of charge and imposes minimal cost to either the state governments or the taxpayers. ${ }^{6}$

When a student is non-compliant, schools are required to notify the Department of Motor Vehicles and Transportation which sends a letter advising the student that he is at risk of losing his driving license unless documentation of compliance is received. The student earns his or her driving privileges back by complying, qualifying for an exemption or waiting until the age of 18 after which the license is no longer conditional on school enrollment. Among the 26 states with an NPND law, 17 condition a student's driving privileges exclusively upon compliance with attendance requirements. For the remaining states, satisfactory academic progress and suspension or expulsion from school are additional requisites.

NPND laws have become a popular, statewide carrot-and-stick approach used to a address truancy and increase high school graduation rates. Barua and VidalFernandez (2014) show that NPND laws led to a 5.1 percent increase in the probability of graduating from high school among Black males. Further, these laws were effective in reducing truancy and increased time allocated to school-work at the expense of leisure and work.

Unfortunately not all states maintain anual records of the number of licenses that get revoked or are threatened to be revoked due to NPND laws. Nonetheless, informal conversations with some of the state departments suggests that the law is strictly enforced and it can affect a significant proportion of teenage drivers. We contacted the Department of Vehicle Motors in all states and managed to gather

\footnotetext{
${ }^{6}$ Source: Kentucky Department of Education and Department of Transportation.
} 
only some anecdotal evidence. For instance, in Florida in 2010, out of about 340,000 drivers under 18, the state suspended 5,389 student licenses for truancy, and sent warnings to another 24,090 students with a learner's permit who were at risk for a delay in getting their license. ${ }^{7}$ Only $4 \%$ of those who got their licenses suspended did not meet the requirements to recover their driving privileges in the next period. The proportion of affected teenagers however varies across states. For example, the same year, Georgia suspended 16,000 licenses out of 90,684 drivers under 18, which accounted for approximately $17 \%$ of potential teenage drivers affected by NPND laws, while in Tennessee the proportion was around 3\% (Southern Regional Education Board, 2011).

Theoretically, the effect of NPND laws on crime is ambiguous and time-dependent. NPND laws can have a deterrence effect by keeping teenagers off the streets or through its effect on education. At the same time, Eckstein and Wolpin (1999) argue that young adults who drop out of high school have lower school ability and/or motivation, place a higher value on leisure and have a lower consumption value of school attendance. Thus, these laws could also have a positive effect on crime if they force marginal students, who are more likely to commit crime, to stay in school. In addition, a potential negative consequence of the law could be that it may encourage teenagers to drive without or fake licenses. This could have high social costs if such drivers are riskier and under-insured. ${ }^{8}$ Moreover, students might be willing to falsify documentation to show compliance. Thus, the net effect of NPND laws will depend on the negative effect on crime through increased human capital and the possible path-dependent increase in traffic-related felonies, in-school crime and forgery.

\footnotetext{
${ }^{7}$ Source: Data tracked by the Florida Department of Motor Vehicles in cooperation with the Florida Department of Education.

${ }^{8}$ This effect can be somewhat mitigated because most states with NPND laws grant exemptions to students who need to work to support their families. Moreover, we have tested this theory using the Fatality Analysis Reporting System (FARS) that maintains data on fatal injuries suffered in motor vehicle traffic crashes in the US. Negative binomial regression models of the effect of NPND law on state level accident fatalities among teenagers using the data yielded negative but statistically insignificant estimates.
} 


\section{Data}

\subsection{FBI Uniform Crime Reports}

To study the effect of NPND laws on crime we use the FBI Uniform Crime Reports (UCR) data from 1988 until 2010. The FBI provides law enforcement agencies with a handbook that explains how to classify and score offenses and provides uniform crime offense definitions across states. The monthly arrests data files gather information on the total number of arrests per 100,000 inhabitants by age, sex, race, and type of crime (murder, rape, property crime, embezzlement, drugs, and driving-related offenses), county and year. ${ }^{9}$ Though arrests are not necessarily a true representation of crimes committed, Lochner and Moretti (2004) find high correlations between different types of crimes committed and arrests. For the rest of the analysis, we use crime and arrests interchangeably.

We add up arrests by state and year for two reasons. First, our policy variable changes only at the state and year levels. Second, not all local agencies report the requested information, which introduces measurement error at the agency and/or county level. Therefore, in addition to state and year fixed effects, our models control for state-specific time trends to account for time changes in geographical reporting rates.

Though we report estimates for all age groups, we restrict our main analysis to compare NPND affected cohorts (16-18 year olds) with those who are closer in age but should not have been affected (20 to 24 year olds $)^{10}$.

Table 2 depicts descriptive statistics of arrests during 1988-2010 by gender and type of crime. The incidence of male arrests among 16 to 18 year olds is particularly high for drug-related crimes, larceny and assault followed by burglary, Driving Under Influence (DUI), motor vehicle thefts and robbery. Among females, the incidence of Larceny arrests are highest followed by assault and drug-related crimes.

\footnotetext{
${ }^{9}$ Note that unlike with the individual survey data of the YRBS, we do not have individual-level FBI data that allows us to conduct an analysis by both gender and race.

${ }^{10}$ Note that younger cohorts might also be affected because they may start investing in their human capital early on to avoid non-compliance later. Although the FBI provides data for crime committed by juveniles below 13 years of age, we restricted the sample to ages above 16 as all our regressions control for age-specific licenses which are only available for 16 years and above.
} 
Table 2: Average yearly arrests 16 to 18 year olds, 1988-2010

\begin{tabular}{lcc}
\hline & Males & Females \\
\hline Violent Crime & 44 & 3 \\
Murder & $(81)$ & $(5)$ \\
& 3 & 0.5 \\
Manslaughter & $(5)$ & $(1)$ \\
& 494 & 39 \\
Robbery & $(962)$ & $(85)$ \\
& 61 & - \\
Rape & $(75)$ & \\
& 1,554 & 570 \\
Assault & $(1,745)$ & $(614)$ \\
& & \\
Property Crime & 2,634 & 1,410 \\
Larceny & $(2,761)$ & $(1,550)$ \\
& 1121 & 106 \\
Burglary & $(1663)$ & $(272)$ \\
& 610 & 76 \\
Motor Vehicle Theft & $(1137)$ & $(140)$ \\
& 37 & 4 \\
Arson & $(41)$ & $(5)$ \\
White Collar Crime & & \\
Forgery & 100 & 52 \\
& $(131)$ & $(67)$ \\
Embezzelment & 19 & 16 \\
& $(33)$ & $(32)$ \\
Drug-Related Crime & & \\
Drugs (sale/manufacture/possessiol & 2937 & 424 \\
Driving Under Influence (DUI) & $(3,994)$ & $(604)$ \\
& 652 & 130 \\
& $(830)$ & $(151)$ \\
\hline
\end{tabular}

In 100,000s. Standard deviations in parentheses

\subsection{Youth Risk Behavior Survey}

We discussed earlier how NPND Laws might have a direct impact on crime through an increase in education. Nonetheless, it may also well be the case that a potential offender with a strong preference for driving returns school to mantain driving privileges while conducting illegal activities in school. Because crime in school is likely to go unreported or sorted out without involving the police, we complement our FBI results with the Youth Risk Behavior Survey (YRBS). The YRBS is a national survey administered by the Centers for Disease Control and Prevention (CDC) every other 
year since 1991. The YRBS gathers information on risky behaviors of young adults in grades 9-12 such as tobacco and alcohol consumption, illegal drug use, and sexual and violent behavior. The objective of the survey is to identify the leading causes of morbidity and mortality among high schoolers within states.

State education and health agencies conduct an almost identical ${ }^{11}$ survey to the YRBS and include limited demographic characteristics that are going to be useful for our analysis such as grade, age, gender and race. While not all fifty states administer the state-level survey each year, since its first release in 1991, the proportion of states joining the survey has steadily increased. We find a link between YRBS survey implementation and the passage of NPND Laws unlikely. Nonetheless, to minimize this concern, we include state, year and time-varying economic (log of real per capita income, unemployment rate and poverty rate) and education controls (student teacher ratio, $\log$ of real teacher's salaries, log of real education expenditures). ${ }^{12}$

The CDC kindly provided us with the state-level surveys for the period 1991 to 2009. Table A1 in the Appendix shows a table with all the states and years for which we were able to gather information. Despite its caveats, the YRBS has been widely used by economists to study range of policy-relevant issues involving sensitive youth behavior topics that are usually limited in other school survey data. ${ }^{13}$

Table 3: Descriptive Statistics of Outcome Variables in YRBS

\begin{tabular}{lccccc}
\hline & Males & Females & Blacks & Whites & All \\
\hline Alcohol & 0.40 & 0.38 & 0.33 & 0.41 & 0.39 \\
& $(0.49)$ & $(0.48)$ & $(0.47)$ & $(0.49)$ & $(0.48)$ \\
Fought in school & 0.17 & 0.08 & 0.17 & 0.11 & 0.13 \\
& $(0.38)$ & $(0.27)$ & $(0.37)$ & $(0.31)$ & $(0.33)$ \\
Felt unsafe in school & 0.12 & 0.04 & 0.08 & 0.07 & 0.08 \\
& $(0.32)$ & $(0.19)$ & $(0.27)$ & $(0.26)$ & $(0.27)$ \\
\hline
\end{tabular}

Standard deviations in parentheses.

Alcohol is a dummy=1 if the respondent had alcohol at least once in the last 30 days. Fought in school=1 if the respondent had atleast one fight in school in the past 12 months. Felt unsafe in school=1 if the respondent did not go to school at least once in the last 30 days because they felt unsafe at school.

\footnotetext{
${ }^{11}$ Some states add additional items in certain years while occasionally some states do not include a set of items asked in the national version of the questionnaire. For example, Utah does not include survey questions related to sex behavior.

${ }^{12}$ Table A.1. in the Appendix provides a list of states which provide publicly accessible data. For additional information about survey methodology of the YRBS see CDC, 2004.

${ }^{13}$ Some examples are Anderson (2014) who analyzes the effects of Compulsory Attendance Laws (CAL) on juvenile crime and Carpenter and Cook (2008) on the effect of cigarette taxes on youth smoking.
} 
Table 3 provides means and standard deviations for the main outcome variables used in the analysis of YRBS data by gender and race. We study three binary outcome variables; "Alcohol" takes the value of 1 if the respondent had alcohol at least once in the last 30 days, "Fought in school" takes the value of 1 if the respondent had at least one fight in school in the past 12 months and "Felt unsafe in school" is equal to 1 if the respondent did not go to school at least once in the last 30 days because they felt unsafe at school.

Males and Blacks are both $17 \%$ likely to have had a fight in school in the past year. Males are three times more likely than females to miss school due to safety concerns and both males and females are equally likely to indulge in underage drinking.

\section{Empirical Strategy and Identification}

To analyze the effect of NPND laws on education our baseline specification (Differencesin-Differences) is as follows:

$$
\log \left(C_{j s t}\right)=\beta_{1} n p n d_{s t}+\beta_{2} X_{s t}+S+A+Y+\varepsilon_{j s t}
$$

where, the outcome $C$ are arrests per 100,000 population by type of crime $j$, age group $a$, state $s$, and year $t$. $n p n d_{s t}$ is a dummy equal to one if the state $s$ has a NPND in place in a particular year. $S, A$ and $Y$ are state, age, and year indicators, respectively. $X_{s t}$ are a range of time-variant state-specific characteristics that control for socioeconomic conditions which can affect crime rates. These include macroeconomic controls, traffic-related control variables and education specific controls. The macroeconomic variables include log of real per capita income, log of male population, unemployment rate, poverty rate and percentage of black population. In addition we also control for log of size of the police force. Education related controls include the student teacher ratio, log of real teacher's salaries, log of real education expenditures and minimum dropout ages. ${ }^{14}$ In the regressions where DUI arrests is the outcome variable, we also control for several traffic-related variables, namely, log of age-specific total number of driving licenses, log of vehicle miles travelled, whether

\footnotetext{
${ }^{14}$ All state level education data has been obtained from the National Center for Education Statistics (NCES). We kindly thank Philip Oreopoulos for providing us with the data on CALs.
} 
there is a graduating licenses law in place, and dummy variables for primary and secondary seat belt laws. All income and expenditure variables are inflation-adjusted and errors are clustered at the state level (Duflo and Mullainathan 2004). We include a vector of linear state-specific time trends in all the FBI regressions.

The crucial identifying assumption in our model (1) is that different types of crime do not vary systematically in the treatment and control states over time in the absence of NPND laws. There could be potential sources of internal validity threats to this conventional identification assumption. First, if crime rates decrease due to other laws that are being enacted around the same time, our estimates would be biased. Second, there could be mean reversion if there was a downward trend in crime in treatment states at the time of the enactment of NPND laws but not in control states. Third, the intervention could be a response to another unobservable factor that simultaneously influences both the NPND laws implementation and crime. For instance, the sudden increase in teen traffic violations could lead to states passing NPND laws. ${ }^{15}$
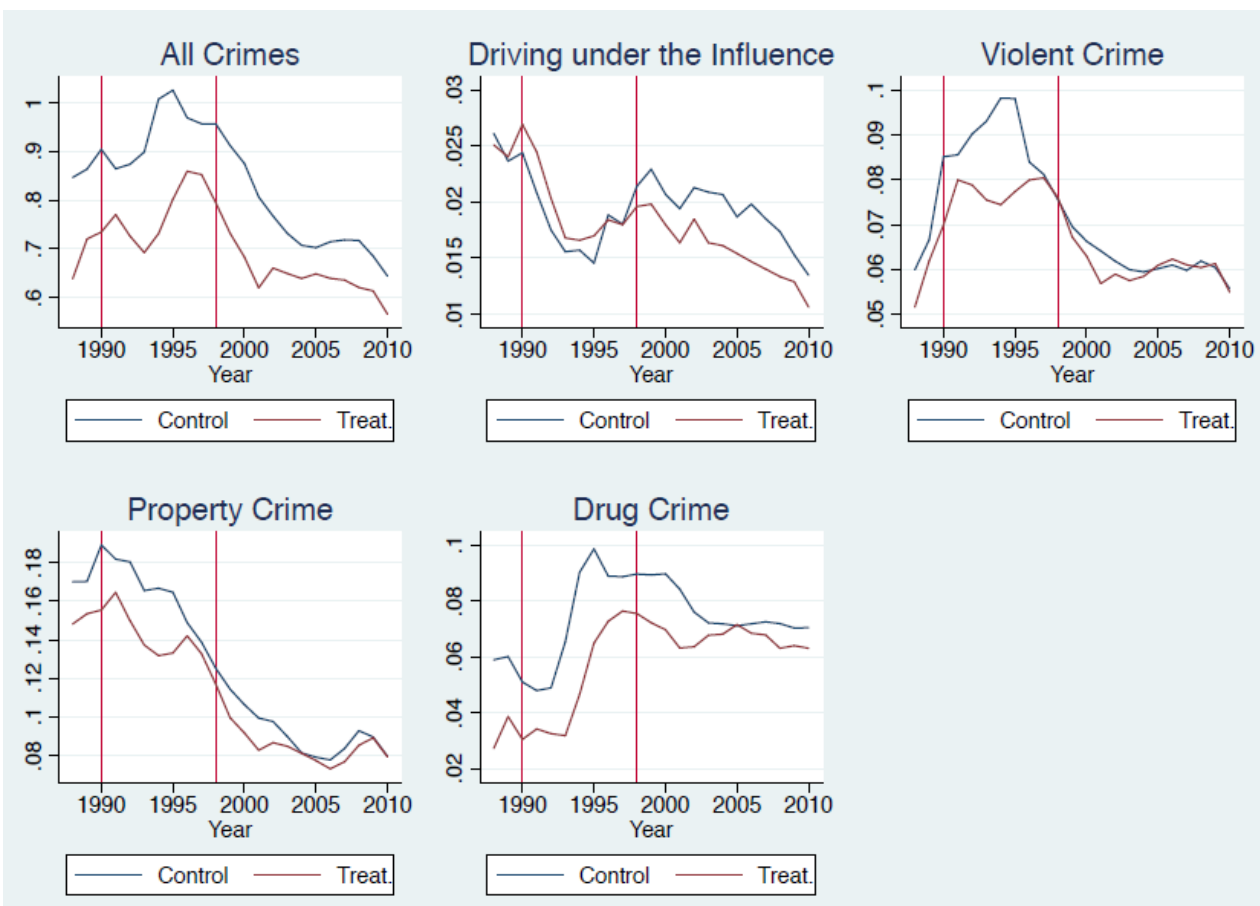

\footnotetext{
${ }^{15}$ NPND laws could also increase the incidence of individuals driving without a valid license. We have unsuccesully tried to gather data about traffic violations from the National Highway Traffic Safety Administration and state-level Departments of motor Vehicles. Nonetheless using the Fatality Analysis Reporting System Data, we do not find any evidence that NPND laws increase traffic fatalities. Results available upon request to the authors.
} 
A first simple visual inspection of average crime trends by year among 16-18 year old males is depicted in Figure 1. The first and second vertical lines in each graph indicate the beginning and ending of the passage of the vast majority of these laws. We can see in the first graph that the pre-trends in overall crime before the implementation in treated and non-treated states are parallel. Furthermore, the difference between treatment and control states shrinks after the passage of NPND laws for DUI, violent, and property crime.

We further address threats to internal validity in several ways. First, we present evidence on the robustness of our key results to introducing a rich set of state-specific demographic, economic, and education characteristics. Second, to address the issue of policy endogeneity caused by traffic related outcomes, we control for state level traffic control variables: the log of vehicle miles traveled, log of total driving licenses, and the log of total motor vehicle fatalities by age group.

Third, we include state-specific linear time trends in the regressions together with dummies for other laws that were being changed or passed in states around the same time such as compulsory attendance laws, graduated driver licensing (GDL) laws and seat belt laws.

Fourth, we argue that the implementation of NPND laws is unlikely to be a systematic response of states desiring to successfully fight against juvenile crime.

Finally, we present results using a more robust specification, namely the triple difference strategy outlined as follows. For this approach, we can rely explicitly on arrest data among older individuals as a more suitable control group to difference out unobserved state and year-specific crime shocks. This second specification exploits the variation in state and year data for 20 to 24 year olds. This control group consists of individuals who are unaffected by the NPND laws because NPND laws only affect those under 18 years of age. ${ }^{16}$ Identification in this "differences-in-differences-indifferences" (DDD) framework relies on comparing the change in the gap between teen (16 to 18 year olds) and young adult (20 to 24 year olds) arrest rates in states that did and did not adopt NPND laws. Thus, consider the following specification:

$$
\log \left(C_{\text {jast }}\right)=\alpha_{1} n p n d_{s t}+\alpha_{2} T C+\alpha_{3} T C * N P N D_{s t}+\alpha_{4} X_{s t}+S+Y+\epsilon_{j a s t},
$$

\footnotetext{
${ }^{16}$ We do not include 19 year olds in the sample because they are in the margin of permissible age and may still be in school.
} 
where TC stands for treated cohort and it is a binary variable that takes the value of 1 if the age group comprises of 16 to 18 year olds and 0 if it comprises 20 to 24 year olds. In this specification, we are interested in $\alpha_{3}$, the coefficient on the interaction between NPND laws and being in a treated cohort (TC).

\section{Results}

\subsection{Effects of NPND on reported crime}

Table 4 shows results for regression (1) by age group and gender. Theoretically, we should expect NPND laws to affect crime in several ways. First, on an average, crimes committed by males may decline. This decline would be attributable to both an increase in education among males and the incapacitation effect from being in school. Second, NPND may increase white-collar types of crime such as forgery of documentation related to licenses. Third, the largest effect should be among young adults between the ages of 16 to 18 .

Among all ages and for both males (column 1) and females (column 3), we observe a significant positive effect on white collar crime as measured by forgery and embezzlement. There is a negative effect on arrests due to drunkenness. Consistent with the aforementioned predictions, the first column in Table 4 shows that in states with NPND laws, 16-18 year old males are less likely to be arrested for manslaughter (0.24 percentage points), robbery (coefficient of 0.16 ), illicit drug possession or sale (0.12) or Driving under the Influence (0.14) whereas the probability of embezzlement increases by 0.3 percentage points. Note that the decrease in DUI arrests could simply be suggesting that the law is restricting teenagers to drive and therefore commit DUI offenses. Among females (column 4), we find a decrease in arrests due to robbery, assaults, stolen property and drug sales/manufacture with percentage point reductions of $0.19,0.11,0.18$ and 0.09 respectively. As with the case of males, white collar crimes such as embezzlement increase by 0.39 percentage points among females.

Examining a large number of outcomes for various subpopulations can derive multiple inference problems and the over-rejection of the null-hypothesis (type I error) increases as additional outcomes are analyzed, even in the absence of a true effect ${ }^{17}$.

\footnotetext{
${ }^{17}$ See Romano and Wolf (2005) for a theoretical analysis of the issue.
} 


\begin{tabular}{|c|c|c|c|c|}
\hline & (1) & (2) & (3) & (4) \\
\hline & All ages Males & 16-18 Males & All ages Females & 16-18 Females \\
\hline \multicolumn{5}{|l|}{ Violent Crime } \\
\hline \multirow[t]{2}{*}{ Murder } & -0.050 & -0.015 & -0.012 & -0.020 \\
\hline & $(0.055)$ & $(0.110)$ & $(0.044)$ & (0.114) \\
\hline$N$ & 9822 & 1799 & 6321 & 844 \\
\hline \multirow[t]{2}{*}{ Manslaughter } & -0.003 & $-0.238^{* *}$ & $0.120 * *$ & 0.057 \\
\hline & $(0.042)$ & $(0.091)$ & $(0.057)$ & $(0.248)$ \\
\hline $\mathrm{N}$ & 5673 & 815 & 2817 & 225 \\
\hline \multirow[t]{2}{*}{ Robbery } & -0.070 & $-0.161^{* *}$ & -0.043 & $-0.192^{* *}$ \\
\hline & $(0.056)$ & $(0.076)$ & $(0.060)$ & $(0.091)$ \\
\hline $\mathrm{N}$ & 10768 & 2183 & 8676 & 1874 \\
\hline \multirow[t]{2}{*}{ Rape } & -0.121 & -0.151 & & \\
\hline & $(0.088)$ & $(0.124)$ & & \\
\hline $\mathrm{N}$ & 11616 & 2198 & & \\
\hline \multirow[t]{2}{*}{ Assault } & -0.018 & -0.082 & -0.012 & $-0.110 * *$ \\
\hline & $(0.048)$ & $(0.055)$ & $(0.042)$ & $(0.049)$ \\
\hline$N$ & 11690 & 2225 & 11287 & 2172 \\
\hline \multicolumn{5}{|l|}{ Property Crime } \\
\hline \multirow[t]{2}{*}{ Larceny } & -0.002 & -0.056 & -0.015 & $-0.118^{*}$ \\
\hline & $(0.042)$ & $(0.042)$ & $(0.053)$ & $(0.065)$ \\
\hline $\mathrm{N}$ & 11754 & 2228 & 11751 & 2227 \\
\hline \multirow[t]{2}{*}{ Burglary } & -0.020 & -0.063 & 0.016 & -0.020 \\
\hline & $(0.050)$ & $(0.048)$ & $(0.058)$ & $(0.074)$ \\
\hline $\mathrm{N}$ & 11477 & 2228 & 10417 & 2195 \\
\hline \multirow[t]{2}{*}{ Motor vehicle theft } & -0.072 & -0.151 & -0.051 & -0.177 \\
\hline & $(0.098)$ & $(0.157)$ & (0.096) & $(0.165)$ \\
\hline $\mathrm{N}$ & 11161 & 2223 & 9488 & 2160 \\
\hline \multirow[t]{2}{*}{ Arson } & 0.013 & 0.037 & 0.062 & -0.084 \\
\hline & $(0.077)$ & $(0.093)$ & $(0.041)$ & $(0.108)$ \\
\hline $\mathrm{N}$ & 10180 & 2074 & 7191 & 1251 \\
\hline \multicolumn{5}{|l|}{ White-Collar Crime } \\
\hline \multirow[t]{2}{*}{ Forgery } & $0.213^{* *}$ & 0.050 & $0.227 * *$ & 0.081 \\
\hline & (0.105) & $(0.074)$ & $(0.105)$ & $(0.112)$ \\
\hline$N$ & 11238 & 2156 & 10742 & 2061 \\
\hline \multirow[t]{2}{*}{ Embezzlement } & $0.231 * *$ & $0.301 * *$ & $0.346 * * *$ & $0.385^{* *}$ \\
\hline & $(0.091)$ & $(0.118)$ & $(0.085)$ & $(0.160)$ \\
\hline $\mathrm{N}$ & 8746 & 1583 & 8494 & 1504 \\
\hline \multicolumn{5}{|l|}{ Drug-Related Crime } \\
\hline \multirow[t]{2}{*}{ Drug sale/manufactuı } & 0.001 & $-0.115^{*}$ & 0.017 & $-0.092^{*}$ \\
\hline & $(0.068)$ & $(0.060)$ & $(0.069)$ & $(0.053)$ \\
\hline $\mathrm{N}$ & 11690 & 2228 & 11452 & 2224 \\
\hline \multirow[t]{2}{*}{ Drug possession } & 0.026 & 0.064 & 0.034 & -0.028 \\
\hline & (0.099) & $(0.182)$ & $(0.086)$ & (0.094) \\
\hline$N$ & 11450 & 2187 & 11054 & 2178 \\
\hline \multirow[t]{2}{*}{ DUI } & -0.009 & $-0.121^{* *}$ & 0.045 & -0.081 \\
\hline & $(0.069)$ & $(0.057)$ & (0.109) & $(0.071)$ \\
\hline $\mathrm{N}$ & 11622 & 2170 & 3875 & 2143 \\
\hline
\end{tabular}

Thus, in Table 5 we present results for all types of crimes added together, violent crimes (murder, rape, robbery, simple and aggravated assaults), property crimes (larceny, burglary, motor vehicle theft, and arson), drug-related crimes (selling, manufacturing and possession) and DUI crimes. In Column (2), Males are 0.06 percentage points less likely to commit all types of crime in states with NPND laws, approxi- 
mately 0.11 percentage points less likely to commit violent crimes and property crimes and 0.12 percentage points less likely to drive under the influence. All of these effects are statistically significant at $5 \%$ level. For females NPND has a negative effect on all crime, violent and property crime with decline being most pronounced for property crimes (0.13 percentage points). Finally, there is a positive and significant effect on white collar crime.

\begin{tabular}{|c|c|c|c|c|}
\hline & $(1)$ & $(2)$ & (3) & (4) \\
\hline & All ages Males & 16 to 18 Males & All ages Females & 16 to 18 Females \\
\hline \multicolumn{5}{|c|}{ All Crime } \\
\hline \multirow[t]{2}{*}{ NPND } & -0.036 & $-0.060 * *$ & -0.005 & $-0.062 *$ \\
\hline & $(0.034)$ & $(0.027)$ & $(0.042)$ & $(0.034)$ \\
\hline Observations & 3950 & 2228 & 3949 & 2227 \\
\hline \multicolumn{5}{|c|}{ Violent Crime } \\
\hline \multirow[t]{2}{*}{ NPND } & $-0.094^{* *}$ & $-0.109 * *$ & -0.079 & $-0.119 *$ \\
\hline & $(0.042)$ & $(0.046)$ & $(0.057)$ & $(0.063)$ \\
\hline Observations & 3950 & 2228 & 3948 & 2226 \\
\hline \multicolumn{5}{|c|}{ Property Crime } \\
\hline \multirow[t]{2}{*}{ NPND } & -0.043 & $-0.103 * *$ & -0.063 & $-0.130 * *$ \\
\hline & $(0.033)$ & $(0.047)$ & $(0.052)$ & $(0.059)$ \\
\hline Observations & 3950 & 2228 & 3949 & 2227 \\
\hline \multicolumn{5}{|c|}{ White Collar Crime } \\
\hline \multirow[t]{2}{*}{ NPND } & -0.019 & -0.108 & $0.098 * *$ & -0.010 \\
\hline & $(0.075)$ & $(0.147)$ & $(0.047)$ & $(0.076)$ \\
\hline Observations & 3945 & 2223 & 3924 & 2203 \\
\hline \multicolumn{5}{|c|}{ Drug Crime } \\
\hline \multirow[t]{2}{*}{ NPND } & -0.049 & 0.063 & -0.051 & -0.034 \\
\hline & $(0.104)$ & $(0.187)$ & $(0.063)$ & $(0.094)$ \\
\hline Observations & 3884 & 2189 & 3875 & 2182 \\
\hline \multicolumn{5}{|c|}{ Driving under Influence } \\
\hline \multirow[t]{2}{*}{ NPND } & -0.009 & $-0.121 * *$ & 0.045 & -0.081 \\
\hline & $(0.069)$ & $(0.057)$ & $(0.109)$ & $(0.071)$ \\
\hline Observations & 11622 & 2170 & 3875 & 2143 \\
\hline \multicolumn{5}{|c|}{ Standard errors clustered at the state level in parentheses. Outcome variable in logs. } \\
\hline \multirow{2}{*}{\multicolumn{5}{|c|}{$\begin{array}{l}* * * p<0.01, * * p<0.05, * p<0.1 \text {. All regressions include state, year, age fixed effects and state-specific } \\
\text { linear time trends. Regressions include full set of state, year specific macroeconomic, traffic (for DUI) }\end{array}$}} \\
\hline & & & & \\
\hline \multicolumn{5}{|c|}{ and education control variables, log of age-specific population and log of age-specific driving licenses. } \\
\hline \multicolumn{5}{|c|}{ Violent crime includes manslaughter, murder, robbery, rape and assaults. } \\
\hline \multicolumn{5}{|c|}{ Property crime includes larceny, burglary, motor vehicle theft and arson. } \\
\hline Drug crimes in & both possession & d sale/manufacture & f drugs. & \\
\hline
\end{tabular}

Table 6, columns (1), (4), (7), (10) and (13) report estimated results from the alternative DDD specification outlined earlier in Equation (2). The main variable of interest is the interaction between NPND laws and the binary variable that equals to 1 if the age group is 16 to 18 and zero for the ages 20 to 24. Although the DD and DDD models rely on different identification assumptions, the results are quite complementary except for the DUI arrests. Both approaches suggest that NPND has significant negative effects on arrests among males. However, the coefficients are more than double (and sometime four times) the DD estimates. Among the affected cohort of male teenagers, there is a 0.24 percentage point reduction in all arrests relative to 
20 to 24 year olds. In columns (4) and (7) there is an approximately 0.19 percentage points decrease in arrests due to property and violent crimes, respectively. The effect on DUI arrests disappears under this specification suggesting that the common trend assumption in the differences-in-differences specification may not be valid for DUI arrests. There is, however, a very large and statistically significant negative effect on drug crimes in column (10) among both males and females (coefficient of 0.29 for males and 0.32 for females). ${ }^{18}$

\begin{tabular}{|c|c|c|c|c|c|c|c|c|c|c|c|c|c|c|c|}
\hline & (1) & (2) & (3) & (4) & (5) & (6) & (7) & (8) & (9) & (10) & (11) & (12) & (13) & (14) & (15) \\
\hline & \multicolumn{3}{|c|}{ All Crime } & \multicolumn{3}{|c|}{ Property Crime } & \multicolumn{3}{|c|}{ Violent Crime } & \multicolumn{3}{|c|}{ Drug Crime } & \multicolumn{3}{|c|}{$\underline{D U I}$} \\
\hline & All & CAL 18 & CAL $<18$ & All & CAL 18 & CAL $<18$ & All & CAL 18 & $\mathrm{CAL}<18$ & All & CAL 18 & CAL $<18$ & All & CAL 18 & CAL $<18$ \\
\hline & \multicolumn{15}{|c|}{ Panel A: Males } \\
\hline \multirow[t]{2}{*}{ NPND*Age16to18 } & $-0.241^{* *}$ & -0.137 & $-0.270^{* * *}$ & $-0.185^{*}$ & 0.014 & $-0.243^{* *}$ & $-0.196 *$ & 0.046 & $-0.272^{* *}$ & $-0.289 * *$ & -0.166 & $-0.312^{* *}$ & -0.244 & -0.392 & -0.239 \\
\hline & $(0.090)$ & $(0.161)$ & $(0.096)$ & $(0.092)$ & $(0.187)$ & $(0.100)$ & (0.099) & $(0.210)$ & $(0.101)$ & $(0.117)$ & $(0.223)$ & $(0.138)$ & (0.146) & (0.417) & $(0.152)$ \\
\hline \multirow[t]{2}{*}{ Observations } & 3204 & 823 & 2381 & 3204 & 823 & 2381 & 3204 & 823 & 2381 & 3151 & 815 & 2336 & 3140 & 798 & 2342 \\
\hline & \multicolumn{15}{|c|}{ Panel B: Females } \\
\hline \multirow[t]{2}{*}{ NPND*Age16to18 } & $-0.201^{*}$ & -0.133 & $-0.205^{*}$ & -0.088 & 0.057 & -0.126 & -0.154 & 0.065 & $-0.200^{*}$ & $-0.325 * *$ & -0.280 & $-0.292 *$ & -0.264 & -0.276 & -0.242 \\
\hline & $(0.112)$ & $(0.164)$ & $(0.115)$ & $(0.093)$ & (0.185) & $(0.091)$ & (0.111) & $(0.230)$ & (0.109) & $(0.127)$ & (0.198) & $(0.147)$ & (0.178) & $(0.354)$ & (0.198) \\
\hline Observations & 3203 & 823 & 2380 & 3203 & 823 & 2380 & 3202 & 823 & 2379 & 3144 & 813 & 2331 & 3113 & 789 & 2324 \\
\hline
\end{tabular}

At this point, it is worth comparing these estimates to those found in the literature. Anderson (2014) finds that a minimum dropout age of 18 decreases arrest rates for all types of crime, property crime and violent crime among 16 to 18 year-olds by approximately 10 to $23 \%$. The estimated effects are usually not statistically significant for drug-related arrests though the magnitudes are very large. Our estimates from the DDD specification are comparable at $24 \%$ for all types of crime, 18.5 percent for property crime and 19.6 percent for violent crime among males. However, we find that NPND laws are associated with a large negative effect on drug crime amounting to a $29 \%$ and $32 \%$ reduction in male and female arrests, respectively. ${ }^{19}$

While our magnitudes are quite large, we should note that there are several channels by which NPND can impact crime rates. First, the law affects students at the margin of dropping out beyond compulsory attendance age. Thus, it is not forcing teenagers to stay in school longer but encourages them to do so if they have a preference for driving. Thus these teenagers are positively selected in comparison with those only affected by compulsory attendance laws.

\footnotetext{
${ }^{18}$ In results not shown here, we find no effect on white collar crime in the DDD specification for either males or females.

${ }^{19}$ Anderson (2014) finds comparable estimates for drug related arrests among males (i.e. of the order of $28 \%$ ). However the effects are statistically insignificant.
} 
Second, most NPND states impose minimum attendance requirements, minimum academic and good behavior standards, in addition to school enrollment which motivates additional human capital accumulation. In fact, Barua and Vidal-Fernandez (2014) find that students who remained in school increased time allocated to schoolwork at the expense of leisure and work hours.

Finally, NPND laws differ from CAL's in the age at which teenagers are affected. It is clear from Table 1 that NPND laws constrains students, who care for driving, to stay in school even beyond the minimum compulsory attendance age. There should be a higher payoff from graduating from school than from attending beyond compulsory attendance and those who are aware are reacting to that. In addition, those who stay in school to retain driving privileges are getting a year or two of additional schooling than those dropping out after CAL which will have an additional effect on crime.

This is confirmed by looking at the remaining columns of Table 6 . We divide the sample by states with a CAL of 18 and those with CAL of less than 18 . None of the coefficients are statistically significant for the states with a minimum dropout age of 18. On the other hand, in states where the dropout age is less than 18, but NPND constrains teenagers to remain in school until graduation, the crime reducing effect of NPND are large and highly significant. These results confirm that NPND laws have large externality effects on crime and are complementary to compulsory attendance laws.

\subsection{Effects of NPND on in-school offenses}

The negative effect of NPND laws on reported crime could be at the expense of an increase in in-school offenses if potential criminals are not deterred nor incapacitated when staying in school to apply or retain their driving licenses. Thus, we study next the effect of NPND laws on crime and substance abuse within schools using the YRBS data.

We show results for three variables that indicate presence of illegal or aggressive activities within school premises: having consumed alcohol or being involved in a fight in school in the last 30 days or feel threatened or unsafe in the last year. Columns 1-4 in Table 7 depict results for males, females, blacks and whites, respectively.

All regressions include state and year fixed effects, the full set of state and yearspecific macroeconomic and education controls used previously in the FBI analysis. 
In addition, we control for age and age-squared. We also control for race (black and white) and gender in columns $1-2$ and $3-4$, respectively. ${ }^{20}$

Table 7: Effect of NPND on School Outcomes by Gender \& Race (YRBS)

\begin{tabular}{lccccc}
\hline & $(1)$ All & $(2)$ Males & (3) Females & $(4)$ Blacks & $(5)$ Whites \\
\hline \multirow{2}{*}{ NPND } & & & Alcohol & & \\
& 0.005 & 0.001 & 0.008 & 0.014 & 0.020 \\
Dropout age & $(0.014)$ & $(0.014)$ & $(0.014)$ & $(0.013)$ & $(0.013)$ \\
& $0.010^{* *}$ & $0.013^{* *}$ & 0.006 & -0.002 & $0.009^{* *}$ \\
Observations & $(0.004)$ & $(0.005)$ & $(0.004)$ & $(0.005)$ & $(0.003)$ \\
& 539022 & 260978 & 278044 & 69138 & 328906 \\
NPND & & & Fought in School & & \\
& 0.005 & 0.011 & -0.001 & 0.016 & -0.003 \\
Dropout age & $(0.004)$ & $(0.007)$ & $(0.005)$ & $(0.011)$ & $(0.006)$ \\
& $0.004^{* * *}$ & $0.005^{* *}$ & 0.002 & 0.000 & 0.001 \\
Observations & $(0.001)$ & $(0.002)$ & $(0.002)$ & $(0.004)$ & $(0.002)$ \\
& 533168 & 259337 & 273831 & 69712 & 320752 \\
NPND & & & Felt Unsafe in School & & \\
& $-0.013^{*}$ & -0.015 & $-0.012^{* * *}$ & -0.007 & -0.010 \\
Dropout age & $(0.007)$ & $(0.012)$ & $(0.004)$ & $(0.007)$ & $(0.008)$ \\
& $0.007^{* *}$ & $0.010^{* *}$ & $0.003^{* *}$ & 0.002 & 0.002 \\
Observations & $(0.003)$ & $(0.004)$ & $(0.001)$ & $(0.003)$ & $(0.002)$ \\
\hline Stand & 527251 & 256716 & 270535 & 70474 & 314396 \\
\hline
\end{tabular}

Standard errors clustered at the state level in parentheses. $* * * p<0.01, * * p<0.05,{ }^{*} p<0$.

Regressions include state, year fixed effects, macroeconomic, traffic and education controls, age and age squared and dummies for Black, White \& Hispanics (for columns 1, 2 \& 3) and gender (1=male) for columns 1, 4 \& 5.

We find no evidence that NPND laws led to an increase in in-school offences. Though the coefficients for alcohol and school fights are positive, they are not statistically significant. In fact, the results suggest that all groups together and females are less likely to miss school due to safety concerns. This finding is consistent with Barua and Vidal-Fernandez (2014) who show that NPND Laws increase the time spent doing homework at the expense of leisure activities and that the effect is also evident within females, most likely due to peer effects.

Table 7 also shows the coefficient on dropout ages for comparison with another related study. Consistent with Anderson et. al. (2014), stricter dropout ages are associated with risky behaviour in school. Individuals in states with stricter minimum

\footnotetext{
${ }^{20}$ Unfortunately we can not replicate the anaylisis by race with the FBI because we do not have access to arrests crimes by age group, state and race. Note also that state-specific trends are not appropiate in these specifications given that, as reported in Table A.1 in the Appendix, states do not conduct YRBS in consecutive years.
} 
attendance regulations are more likely to consume alcohol, engage in fights and miss school due to safety concerns. The results are predominantly driven by males. Thus, as opposed to NPND laws, students are more likely to report risky behavior in school when the minimum dropout age is higher.

\section{Discussion}

We study the effect of NPND laws, a policy encouraging teenagers with a preference for driving to stay in school beyond the minimum dropout age, on an important education externality, namely, crime. Using a difference-in-difference-in-differencetype empirical strategy and data from the Federal Bureau of Investigation (FBI), we find that NPND laws led to a significant decline in arrests due to violent, property and drug crimes among males. We find a decline of $24 \%$ for all types of crime, 18.5 percent for property crime and 19.6 percent for violent crime among males. Moreover, NPND laws are associated with a large negative effect on drug crime amounting to a $29 \%$ and $32 \%$ reduction in male and female arrests, respectively.

Further, analyzing data from a school level survey that gathers information on risky behaviors of young adults in grades 9-12, we find some evidence that our results are not driven by the incapacitation effect. Moreover, we argue that NPND laws are a relatively low cost policy that increases education and generates positive externalities beyond and in addition to the minimum drop out age laws. Following the estimates by Lochner and Moretti (2004), these laws could save the public up to 4 billion through social savings from crime reduction.

Finally, this results sheds light on the possibility that policies targeted at increasing education within disadvantaged teenagers might not only decrease crime but also be very cost-effective (Fryer 2016). 


\section{References}

1. Anderson, D.M. 2014. In School And Out of Trouble? The Minimum Dropout Age and Juvenile Crime. The Review of Economics and Statistics 96(2):318331.

2. Anderson, D.M., B Hansen, MB Walker. 2013. The minimum dropout age and student victimization. Economics of Education Review 35, 66-74

3. Ayres, B. Drummond. 1989 "West Virginia Reduces Dropouts by Denying them Driver's license". The New York Times, 21st May 1989.

4. Barua, R. and M. Vidal-Fernandez 2014. No Pass, No Play: Negative Incentives and Allocation of Time. The Journal of Human Capital 8 (4): 399-43.

5. Becker, G. S. and C.B. Mulligan. 1997. The Endogenous Determination of Time Preference. The Quarterly Journal of Economics 112(3): 729-58.

6. Bertrand, M., Duflo E. and S. Mullainathan, 2004. How Much Should We Trust Differences-in-Differences Estimates? The Quarterly Journal of Economics 119(1): 249-275.

7. Carpenter, C. and P. Cook. 2008. Cigarette Taxes and Youth Smoking: New Evidence from National, State, and Local Youth Risk Behavior Surveys. Journal of Health Economics 27(2): 287-299.

8. Centers for Disease Control and Prevention. 2004. Methodology of the Youth Risk Behavior Surveillance System. Morbidity and Mortality Weekly Report 53: $1-14$.

9. Cullen J.B., B.A.Jacob, and S. Levitt, 2006. The Effect of School Choice on Participants: Evidence from Randomized Lotteries. Econometrica 74(5): 11911230.

10. Deming, D. J., 2011. Better Schools, Less Crime. Quarterly Journal of Economics 126 (4): 2063-2115.

11. Eckstein, Z., \& Wolpin, K., 1999. Why youths drop out of high school: The impact of preferences, opportunities and abilities. Econometrica, 67(6), 12951340 . 
12. Freeman, R.B. 1999. The Economics of Crime. O. Ashenfelter \& D. Card (ed.), 1999. Handbook of Labor Economics, Elsevier Science, Volume 3, Chapter 2.

13. Fryer, R. 2016. The Production of Human Capital in Developed Countries. Evidence from 196 Randomized Experiments. NBER Working Paper 22130.

14. Jacob, B. and Lefgren, L. 2003. Are idle hands the devil s workshop? Incapacitation, concentration and juvenile crime. American Economic Review, vol. 93, pp. $1560-77$.

15. Jensen, R. and Lleras-Muney, A. 2012. Does Staying in School (and not Working) prevent Teen Drinking and Smoking? Journal of Health Economics 31(4): 644-647.

16. Lochner, L. and E, Moretti, 2004. The Effect of Education on Crime: Evidence from Prison Inmates, Arrests, and Self-Reports. The American Economic Review 94(1): 155-189.

17. Lochner, L. 2011a. Education Policy and Crime. Published in Controlling Crime: Strategies and Tradeoffs, Cook, Ludwig, and McCrary. 2011.

18. Lochner, L. 2011b. Non Production Benefits of Education: Crime, Health, and Good Citizenship. E. Hanushek, S. Machin and L. Woessmann (eds.), Handbook of the Economics of Education, Vol. 4, Chapter 2, Amsterdam: Elsevier Science.

19. Luallen, J. 2006. School's out... forever: a study of juvenile crime, at-risk youths and teacher strikes. Journal of Urban Economics, vol. 59, pp. 75-103.

20. Machin, Stephen J. and Marie, Olivier and Vujic, Suncica. 2011. The Crime Reducing Effect of Education. The Economic Journal, Vol. 121, Issue 552, pp. 463-484.

21. Patacchini, E., and Y. Zenou. 2009. Juvenile Delinquency and Conformism. Journal of the Law, Economics, and Organization 26 (3).

22. Ramirez, J. M. and J.M. Andreu Rodríguez, 2006. Aggression, and some related psychological constructs (Anger, Hostility, and Impulsivity): comments from a research project. Neuroscience and Biobehavioural Reviews 30 (3): 276-291. 
23. Romano, J.P. and M. Wolf, 2005. Stepwise multiple testing as formalized data snooping. Econometrica 73 (4): 1237-1282.

24. Southern Regional Education Board. 2011. "Strengthening Attend 'n' Drive Laws to Reduce Truancy and Dropouts". SREB Policy brief.

25. U.S. Department of Education. State Comparisons of Education Statistics: 1969-70 to 1996-97. NCES 98-018, Washington DC: 1998.

26. U.S. Department of Education, National Center for Education Statistics. (2014). The Condition of Education 2014 (NCES 2014-083), Status Dropout Rates.

27. U.S. Department of Education, Digest of Education Statistics, National Center for Education Statistics. 2009, 2010. 


\section{Appendix}

Table A.1: Youth Risk Behavior Surveillance System Publicly Available Data $\square$

\begin{tabular}{|c|c|c|c|c|c|c|c|c|c|}
\hline State & 2007 & 2005 & 2003 & 2001 & 1999 & 1997 & 1995 & 1993 & 1991 \\
\hline Alabama & 0 & 1 & 1 & 1 & 1 & 1 & 1 & 1 & 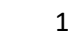 \\
\hline Alaska & 1 & 0 & 1 & 0 & 0 & 0 & 1 & 0 & \\
\hline Arkansas & 1 & 1 & 0 & 1 & 1 & 1 & 1 & 0 & \\
\hline Connecticut & 1 & 1 & 0 & 0 & 0 & 1 & 0 & 0 & \\
\hline Delaware & 1 & 1 & 1 & 1 & 1 & 0 & 0 & 0 & \\
\hline lowa & 1 & 1 & 0 & 0 & 0 & 1 & 0 & 0 & \\
\hline Idaho & 1 & 1 & 1 & 1 & 0 & 0 & 0 & 1 & \\
\hline Illinois & 1 & 0 & 0 & 0 & 0 & 0 & 1 & 1 & \\
\hline Kansas & 1 & 1 & 0 & 0 & 0 & 0 & 0 & 0 & \\
\hline Kentucky & 0 & 1 & 1 & 0 & 0 & 0 & 0 & 0 & \\
\hline Lousiana & 1 & 0 & 0 & 0 & 0 & 0 & 0 & 0 & \\
\hline Maryland & 1 & 1 & 0 & 0 & 0 & 0 & 0 & 0 & \\
\hline Maine & 1 & 1 & 1 & 1 & 0 & 1 & 1 & 0 & \\
\hline Missouri & 1 & 1 & 1 & 1 & 1 & 1 & 1 & 0 & \\
\hline Mississippi & 1 & 0 & 1 & 1 & 1 & 1 & 1 & 1 & \\
\hline Montana & 1 & 1 & 0 & 1 & 1 & 1 & 1 & 0 & \\
\hline North Carolina & 1 & 1 & 1 & 1 & 0 & 0 & 1 & 1 & \\
\hline North Dakota & 1 & 1 & 1 & 1 & 1 & 0 & 1 & 0 & \\
\hline Nebraska & 0 & 1 & 1 & 0 & 0 & 0 & 0 & 1 & \\
\hline New Jersey & 1 & 1 & 0 & 1 & 0 & 0 & 0 & 0 & \\
\hline NY & 1 & 1 & 1 & 0 & 1 & 1 & 0 & 0 & 0 \\
\hline Oklahoma & 1 & 1 & 1 & 0 & 0 & 0 & 0 & 0 & 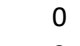 \\
\hline Rhode Island & 1 & 1 & 1 & 1 & 0 & 1 & 0 & 0 & \\
\hline South Carolina & 1 & 1 & 0 & 0 & 1 & 1 & 1 & 1 & \\
\hline South Dakota & 1 & 1 & 1 & 1 & 1 & 1 & 1 & 0 & $\perp$ \\
\hline Tennessee & 1 & 1 & 0 & 0 & 0 & 0 & 0 & 1 & 0 \\
\hline Utah & 1 & 1 & 1 & 1 & 1 & 1 & 1 & 1 & \\
\hline Wisconsin & 1 & 1 & 1 & 1 & 1 & 1 & 0 & 1 & U \\
\hline West Virginia & 1 & 1 & 1 & 0 & 1 & 1 & 0 & 1 & \\
\hline Wyoming & 1 & 1 & 0 & 1 & 1 & 0 & 1 & 0 & \\
\hline
\end{tabular}

Arizona, Colorado, Florida, Georgia, Hawaii, Indiana, Massachussetts, Michigan,

Nevada, New Hamphhire, New Mexico, Ohio, Texas and Vermont did not provide the

CDC permission to share their data. 